\title{
THE OCCURRENCE OF ACID MUCOPOLYSACCHARIDES IN HUMAN LEUKOCYTES AND URINE ${ }^{1}$
}

\author{
BY GRACE P. KERBY \\ (From the Department of Medicine, Duke University School of Medicine, Durham, N. C.)
}

(Submitted for publication June 10, 1955; accepted August 17, 1955)

Acid mucopolysaccharides have been found in urine (1) but have not been consistently demonstrated in the blood of normal subjects. Bassiouni (2) recently isolated a substance from leukocytes which he noted to be similar to chondroitin sulfate. In our laboratory leukocytes have been found to contain appreciable quantities of a substance resembling chondroitin sulfate. A direct relationship between this substance and the similar substance found in the urine has not been established.

\section{METHODS}

Subjects. Human subjects were used. These were hospital and laboratory personnel and patients who were unselected except for the omission of individuals with primary hematologic, metabolic, or rheumatic diseases.

Preparation of leukocytes. Siliconed needles, syringes, and glassware were used throughout the preparation until the step in which the cells were deliberately disintegrated. Venous blood (40 to $70 \mathrm{ml}$.) was drawn and distributed immediately in $10-\mathrm{ml}$. amounts to tubes containing $1.0 \mathrm{ml}$. of 5 per cent sodium citrate in a balanced salt solution. ${ }^{2}$ The red blood cells were sedimented rapidly by mixing $2.5 \mathrm{ml}$. of 5 per cent dextran with the blood in each tube. ${ }^{3}$ The supernatant leukocyte-platelet suspension in plasma was centrifuged at $85 \mathrm{~g}$ for $7 \mathrm{~min}$ utes, and the sedimented leukocytes were washed gently one time in $11.0 \mathrm{ml}$. of physiologic saline. Following recentrifuging, they were then pooled in $20 \mathrm{ml}$. of saline, counted, made up to $25 \mathrm{ml}$. with saline in process of transferring to a Raytheon Sonic Oscillator, and oscillated at 9 Kc. per second for 8 minutes.

Isolation of acid mucopolysaccharides from leukocytes.

1 This work was supported in part by research grants from the National Institute of Arthritis and Metabolic Diseases of the National Institutes of Health, Public Health Service, the Duke University Research Council, the American Heart Association, the North Carolina Heart Association and the Baxter Laboratories, Inc.

2 Ten-ml. stock solution (7.5 per cent $\mathrm{NaCl}, 0.75$ per cent $\mathrm{KCl}, 0.1$ per cent $\mathrm{Na}_{2} \mathrm{HPO}_{4}, 0.12$ per cent $\mathrm{KH}_{2} \mathrm{PO}_{4}$, 0.05 per cent $\mathrm{K}_{2} \mathrm{HPO}_{4}$ ) and $7 \mathrm{ml}$. 1 per cent $\mathrm{Na}_{2} \mathrm{HPO}_{4}$ per $100 \mathrm{ml}$., aqueous.

3 Salt free Dextran-Benger Batch 3526/1, made up to final salt concentration of the balanced salt solution described.
The oscillated material was made up to $50 \mathrm{ml}$. with saline, and $3 \mathrm{ml}$. of an aqueous mixed salt solution ${ }^{4}$ were added. Acid mucopolysaccharides were then separated by the method of Astrup (3). ${ }^{5}$

Isolation of acid mucopolysaccharides from urine was accomplished as described in (1), except that collections of urine were made over a standard 3-hour period, samples were dialyzed before fractionation, and an aqueous mixed salt solution ( 17 per cent $\mathrm{NaCl}, 1.5$ per cent $\mathrm{Na}_{2} \mathrm{SO}_{4}$ ) was added to each sample before fractionation (4).

Quantitative studies of acid mucopolysaccharides. On most samples of blood either a hexuronic acid or hexosamine determination was done. When possible both measurements were made on the same blood. The hexuronic acid content of the Astrup fraction was determined as in previous studies (1) by acid hydrolysis and production of the carbazole color reaction of Dische (5). The hexosamine content was determined by the method of Elson and Morgan (6), using redistilled acetylacetone and recrystallized p-dimethylaminobenzaldehyde. Prior hydrolysis of each sample for hexosamine determination was carried out by heating $3 \mathrm{ml}$. of sample with $1 \mathrm{ml}$. of $12 \mathrm{~N}$ hydrochloric acid in a sealed ampule for 15 hours in a $100^{\circ}$ C. steam bath. The samples were then carefully neutralized with $\mathrm{NaOH}$ prior to determination of hexosamine content. ${ }^{6}$ Standards of 40,60 , and 80 gamma of n-acetylglucosamine per ml. were similarly hydrolyzed and run as a standard curve with each set of determinations.

Qualitative studies of the acid mucopolysaccharides. Chromatographic studies were carried out by the same method as has been described previously (1) in studying urine fractions. Electrophoretic studies were done by the method of Pasternak and Kent (7), using versene-washed Whatman No. 1 paper, barbiturate buffer ( $\mathrm{pH} 8.5,0.06 \mathrm{M}$ ), and $0.8 \mathrm{ma}, 105$ volts for 5 hours. The leukocyte and urine samples were prepared for chromatography and electrophoresis as follows: The Astrup fraction was dialyzed against 20 volumes of distilled water with constant rotation for 15 hours at $5^{\circ} \mathrm{C}$. The contents of the dialysate casing were then dried

417 per cent $\mathrm{NaCl}, 3.5$ per cent $\mathrm{NaH}_{2} \mathrm{PO}_{4}, 1.5$ per cent $\mathrm{Na}_{2} \mathrm{SO}_{4}, 3$ per cent $\mathrm{KCl}$.

5 The filtration step after separation with ether was omitted.

6 This step was accomplished by neutralization of an aliquot with $0.3 \mathrm{~N} \mathrm{NaOH}$, then neutralization of the test sample with $3 \mathrm{~N} \mathrm{NaOH}$, to avoid excessive dilution of the sample. 


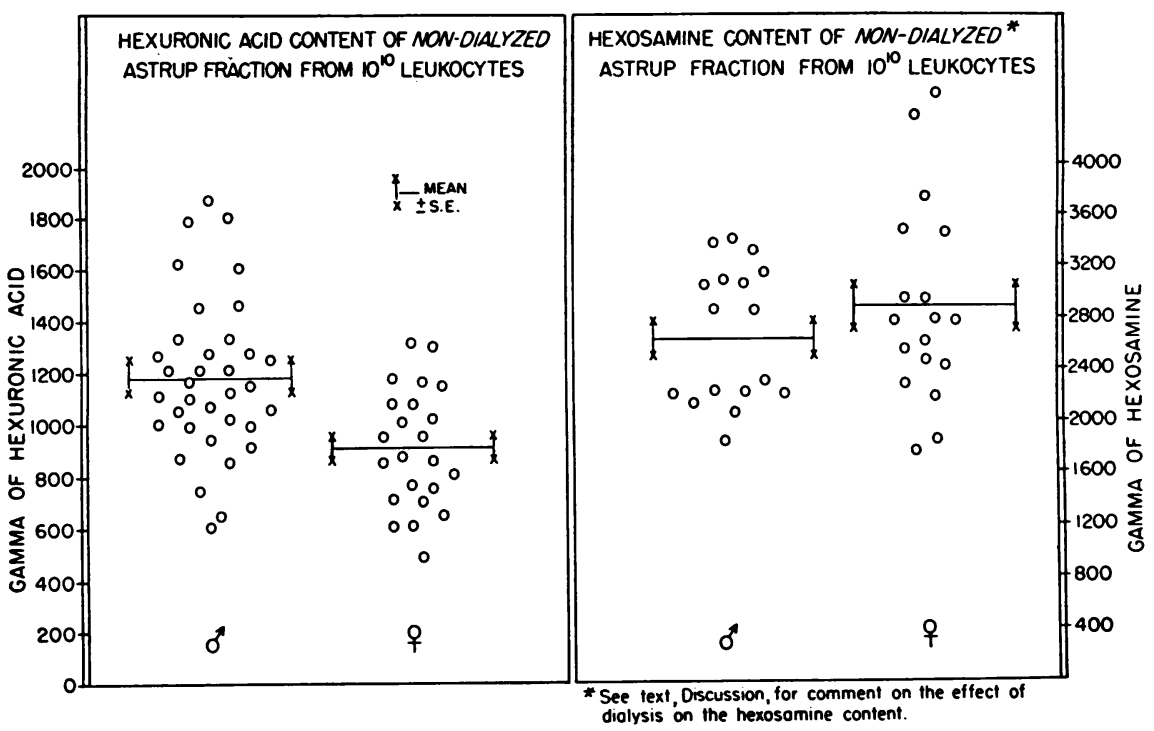

Fig. 1. Hexuronic Acid and Hexosamine Yields from Non-Dialyzed Astrup Fraction of Human Leukocytes

rapidly in a Virtis Freeze-Dryer and taken up in 0.1 to $0.2 \mathrm{ml}$. of distilled water. On filter paper the material stained metachromatically with toluidine blue. Chromatographic and electrophoretic papers were stained with toluidine blue (8). Chondroitin sulfate (General Biochemicals, Inc.) and heparin (Liquaemin; Organon, Inc.) were used for comparison with the test samples.

\section{RESULTS}

Quantitative data for leukocytes prior to dialysis of the Astrup fraction are summarized in Figure 1. Data are expressed as gamma of hexuronic acid or of hexosamine per $10^{10}$ leukocytes (a quantity said by Rossiter and Wong (9) to have a wet weight of about 4 grams).$^{7}$ An Astrup fraction sample representing the residual sample pooled from many donors (male and female) was analyzed before and after dialysis of the Astrup fraction (Table I). It is apparent that the hexuronic acid content of the Astrup fraction was unaffected by dialysis. However, the relatively high hexosamine content was significantly reduced by dialysis. Using the calculated values of Dziewiatkowski (10) of 37.3 per cent uronic acid and 34.4 per cent hexosamine in sodium chondroitin sulfate, the hexosamine content after dialysis was

\footnotetext{
7 The amount present per sample analyzed was usually of the order of magnitude of 10 gamma. An absorption spectrum was run on each sample, routinely, and the sample was discarded if the color which developed differed from that of glucuronic acid alone.
}

twice the expected value for the amount of hexuronic acid present.

Figure 2 illustrates chromatograms comparing acid mucopolysaccharides of commercial source with those of human origin isolated from urine and leukocytes. It will be noted that the urine fraction shows inhomogeneity, as does the commercial preparation of chondroitin sulfate, with the major component of each exhibiting the same $R_{f}$ value as does the single spot given in this range by the leukocyte fraction. The leukocyte fraction shows in addition some material remaining at the starting line, unlike the urine fraction. This material tended to stain orthochromatically with toluidine blue and could be moved out from the starting line with other solvent systems. It is at present unidentified. Residual material was not evident with the leukocyte fraction on paper electrophoresis (Figure 3), the entire fraction moving to form

TABLE I

Content of hexosamine and hexuronic acid in non-dialyzed and dialyzed samples of pooled Astrup fractions derived from leukocytes of human males and females

\begin{tabular}{lcc}
\hline \hline & \multicolumn{2}{c}{$\begin{array}{c}\text { Gamma per ml. of pooled } \\
\text { Astrup fraction }\end{array}$} \\
\cline { 2 - 3 } & Hexosamine & $\begin{array}{c}\text { Hexuronic } \\
\text { acid }\end{array}$ \\
\hline Non-dialyzed & 19.37 & 8.58 \\
Dialyzed & 15.56 & 8.89
\end{tabular}




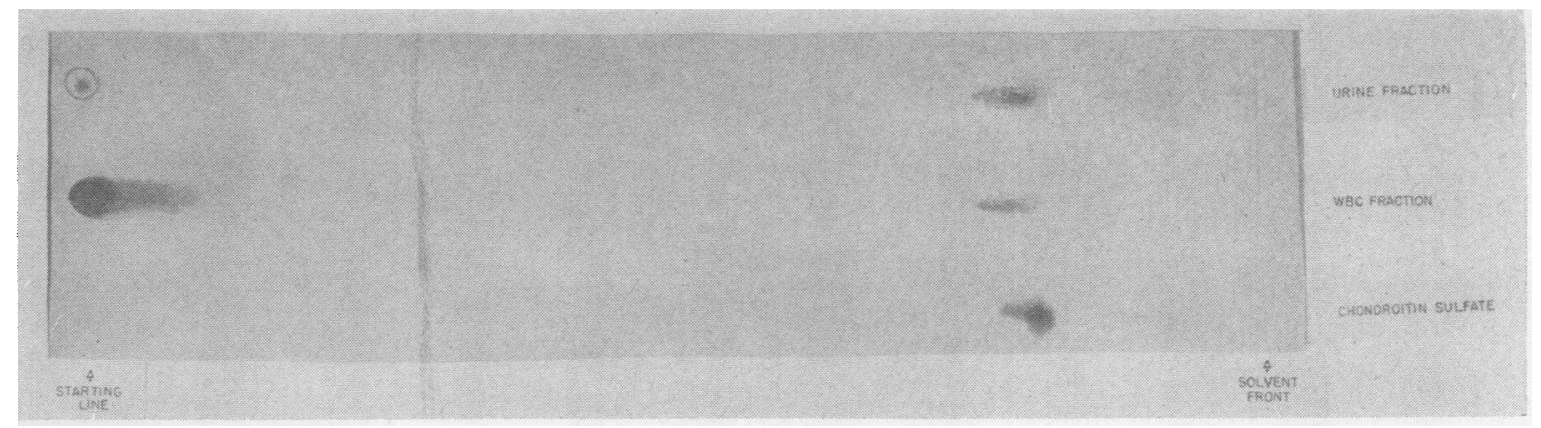

Fig. 2. Chromatographic Comparison of Human Leukocyte and Urine Fractions with Commercial Chondroitin Sulfate

Solvent 50 per cent ethanol in $\mathrm{pH} 6.5 \mathrm{M} / 15$ phosphate buffer.

a single spot corresponding to that formed by commercial chondroitin sulfate. The urine fraction, on the other hand, could not be shown to move as a single spot on paper electrophoresis; a streak was formed, the forward portion of which moved at a slightly slower rate than did chondroitin sulfate. ${ }^{8}$

\section{DISCUSSION}

Human leukocytes were found to contain appreciable quantities of non-dialyzable material which contained hexuronic acid and hexosamine and which was in final step separated from leukocytes by a method (3) which permitted quantitative recovery of added acid mucopolysaccha-

${ }^{8} \mathrm{Dr}$. Karl Meyer is very kindly in the process of analyzing the urine fraction at this time. These data will be published separately. rides. ${ }^{9}$ Chromatographically, the material exhibited a major component which had the same $\mathrm{R}_{\mathrm{f}}$ value as the major component of a similar material previously described (1) isolated from human urine. This $R_{f}$ value was the same, also, as that of the major component of chondroitin sulfate of commercial source. On paper electrophoresis, also, the material from leukocytes formed a spot coinciding with that formed by commercial chondroitin sulfate. The material from leukocytes was considered most probably an acid mu-

9 In a control experiment, leukocytes + saline yielded 3.6 gamma of hexuronic acid, saline + chondroitin sulfate, 9.8 gamma, leukocytes + chondroitin sulfate 13.3 gamma. In a control experiment, leukocytes + saline yielded 10.3 gamma of hexosamine, saline + chondroitin sulfate 12.0 gamma, leukocytes + chondroitin sulfate 19.6 gamma. Absorption spectra were run on all samples, as usual.

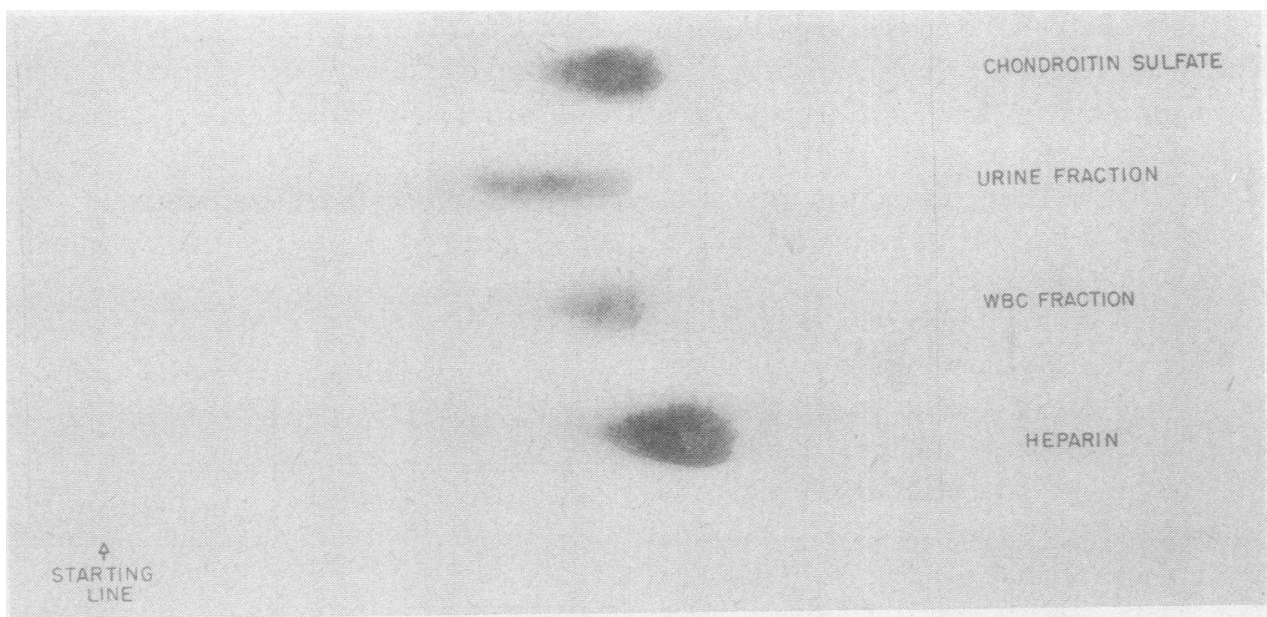

Fig. 3. Electrophoretic Comparison of Human Leukocyte and Urine Fractions with Commercial Chondroitin Sulfate and Heparin 
copolysaccharide on the basis of the findings. Quantitatively, the material pooled from leukocytes of both males and females yielded after dialysis about half the expected carbazole value for hexuronic acid, since equimolar amounts of hexuronic acid and hexosamine are to be expected in most acid mucopolysaccharides. The hexuronic acid content ${ }^{10}$ was unchanged by dialysis, whereas appreciable amounts of hexosamine were lost on dialysis. ${ }^{11}$ In considering relative amounts of acid mucopolysaccharides in leukocytes, therefore, the hexuronic acid content is the more valid of the two quantitations done on nondialyzed Astrup fractions (as summarized in Figure 1). The difference in hexuronic acid content of the acid mucopolysaccharides of leukocytes from males and females was small but significant $(\mathrm{p}<0.01)$.

The previously described material from urine (1) is similarly regarded as probably being an acid mucopolysaccharide. However, dialysis studies subsequent to the previous report (Table II) have shown that there are present also in the Astrup fraction dialyzable glucuronic acid compounds thus far not identified and not components of acid mucopolysaccharides. These account frequently but not always for the increased Astrup fraction in the urine of diabetics (4). They account also for the bulk of the increase in Astrup fraction following the ingestion of glucuronolactone and for the increased amount of Astrup fraction in the urine of human males compared to females. The

10 Follette, Valentine, Hardin, and Lawrence (11) used a naphthoresorcinol method for measuring hexuronic acids of leukocytes in contrast to the carbazole method of the present study, so direct comparisons may not be justifield. However, it is of interest that they noted a total glucuronic acid content of 3,655 gamma per $10^{10}$ leukocytes (mean value) with range of 2,720 to 5,120 gamma. Thus, perhaps about one-third of the total glucuronic acid content of leukocytes can be accounted for in the acid mucopolysaccharide fraction.

11 The identity of the dialyzable hexosamine component is not known. As noted in Figure 1 (representing yields of hexuronic acid and hexosamine from nondialyzed Astrup fraction), the quantity of dialyzable hexosamine was probably greater in samples from females than from males. This observation is based on the data presented in Figure 1, assuming that the proportion of hexosamine to hexuronic acid is stable after dialysis and having determined that the hexuronic acid content is unchanged on dialysis. The assumption is reasonable but not validated at present.
TABLE II

Content of hexosamine and hexuronic acid in Astrup fractions of non-dialyzed and dialyzed 3-hour human urine collections

\begin{tabular}{|c|c|c|c|c|}
\hline \multirow[b]{2}{*}{ Urines } & \multicolumn{4}{|c|}{$\begin{array}{c}\text { In Astrup fraction of 3-hour urine } \\
\text { (gamma) ( } \pm \text { S.D.) }\end{array}$} \\
\hline & $\begin{array}{l}\text { Sub- } \\
\text { jects }\end{array}$ & $\begin{array}{l}\text { Hexuronic } \\
\text { acid }\end{array}$ & $\begin{array}{l}\text { Sub- } \\
\text { jects }\end{array}$ & Hexosamine \\
\hline $\begin{array}{l}\text { Non-dialyzed } \\
\text { Dialyzed }\end{array}$ & $\begin{array}{l}11 \text { ठ } \\
13 \text { ठ }\end{array}$ & $\begin{array}{l}887 \pm 186 \\
375 \pm 136\end{array}$ & $\begin{array}{r}6 \sigma^{7} \\
13 \sigma^{7}\end{array}$ & $\begin{array}{r}1,540 \pm 191 \\
908 \pm 292\end{array}$ \\
\hline $\begin{array}{l}\text { Non-dialyzed } \\
\text { Dialyzed }\end{array}$ & $\begin{array}{rl}8 & \% \\
14 & 9\end{array}$ & $\begin{array}{l}557 \pm 83 \\
301 \pm 84\end{array}$ & $\begin{aligned} 6 \% \\
14\end{aligned}$ & $\begin{array}{r}1,060 \pm 273 \\
791 \pm 265\end{array}$ \\
\hline
\end{tabular}

remaining non-dialyzable material yielded a comparatively low carbazole value for hexuronic acid. Electrophoretically, on paper, it moved poorly, with formation of a streak rather than a spot, unlike commercial chondroitin sulfate. Further work is in progress to establish the identity of the non-dialyzable, acid mucopolysaccharide-like material. It is to be emphasized that the studies reported here on both leukocytes and urine were done on dialyzed but otherwise unpurified materials.

The relationship of acid mucopolysaccharides of leukocytes to the somewhat similar substance found in urine is conjectural at present. Thomas and Good (12) showed that the bilateral cortical necrosis of the generalized Shwartzman reaction which is associated with the occurrence in glomerular capillaries of Hotchkiss-Schiff staining hyaline material could be prevented in rabbits by first rendering the animals leukopenic by the use of nitrogen mustard. The cortical necrosis was not prevented when the lower extremities were protected by circulatory occlusion from the effects of nitrogen mustard, the extremities later being permitted to contribute normal leukocytes and perhaps other materials to the general circulation. The hyaline material which they observed in the glomerular capillaries of these animals with cortical necrosis was thought to be a mucopolysaccharide because of its histochemical characteristics. It cannot be said from their data whether the material was deposited or originated at the site of occurrence. Mucopolysaccharide similar to that isolated from urine and leukocytes in the present study can be demonstrated readily also in beef kiclney tissue (Figure 4) and in all likelihood in kiclney tissue of other species. However, in view of the fact that leukocytes (or other body com- 


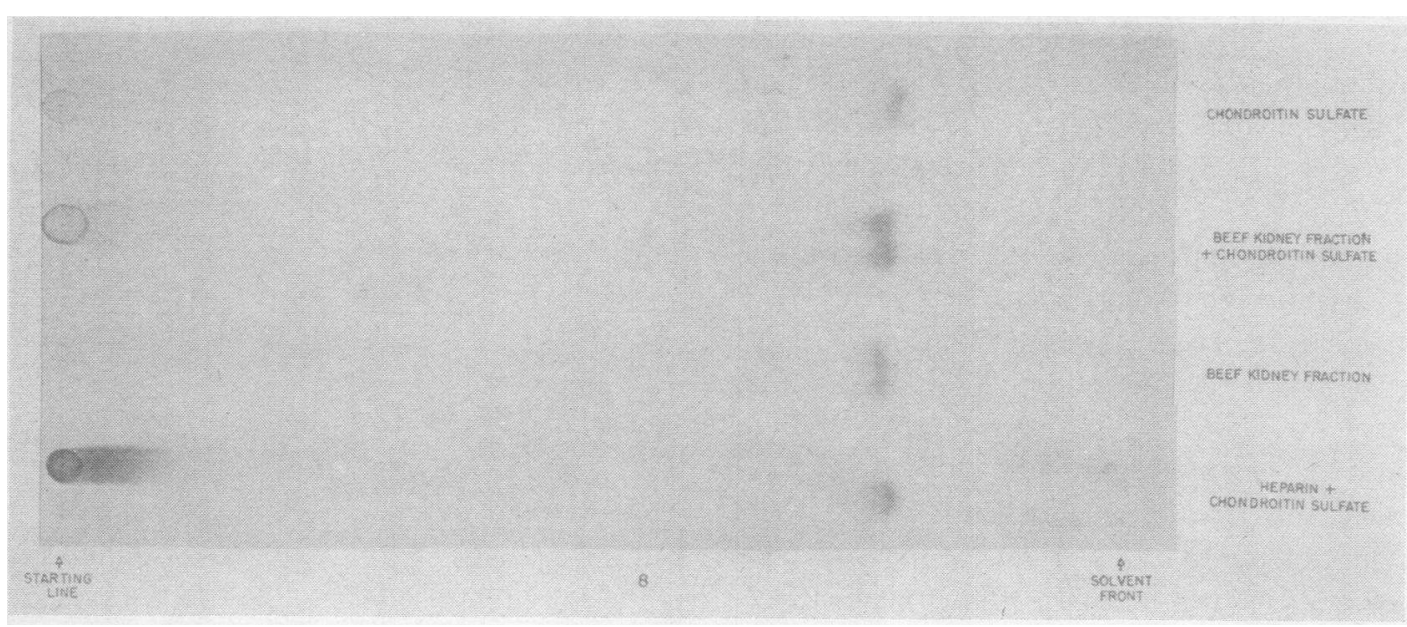

Fig. 4. Chromatographic Comparison of Beef Kidney Fraction with Commercial Chondroitin Sulfate and Heparin

Solvent 50 per cent ethanol in $\mathrm{pH} 6.5 \mathrm{M} / 15$ phosphate buffer.

ponents susceptible to elimination or alteration by nitrogen mustard) appear to be essential for the production of the lesion described by Thomas and Good, it is tempting to postulate a connection between the mucopolysaccharides found in leukocytes and the hyaline mucopolysaccharide-containing material observed in the glomerular lesions.

The question of whether the acid mucopolysaccharides of leukocytes contribute to the somewhat similar material found in normal urine remains unanswered. When several rabbits were made leukopenic with nitrogen mustard, their urinary excretion of acid mucopolysaccharides persisted unchanged. However, they were not severely leukopenic at this time, total leukocyte counts being 680 and 1,240 (compared to baseline counts of 7,750 and 6,800$)$ per $\mathrm{cmm}$., respectively, in the only two animals maintaining their previous level of urine output during the period of observation.

It is entirely possible that the acid mucopolysaccharides of leukocytes simply contribute to the structure of the cell. If so, there remains to be investigated whether abnormalities of content or composition of the material in the leukocyte can be demonstrated in disease states and whether such abnormalities would reflect changes going on simultaneously in other less accessible tissues of the body. Preliminary observations in a variety of disease states, including some of the connective tissue diseases, have not as yet revealed consistent quantitative differences.

\section{SUM MARY}

1. A non-dialyzable material (or materials) containing hexuronic acid and hexosamine has been separated from human leukocytes and urine by a method which permits quantitative recovery of added acid mucopolysaccharides. The material from both sources yielded a low carbazole value for hexuronic acid as compared to hexosamine yield. Chromatographically the material showed resemblance in its properties to certain components of the inhomogeneous commercial chondroitin sulfate with which it was compared. Electrophoretically on paper, also, the leukocyte material resembled commercial chondroitin sulfate in its migration. The urine material differed, forming a slower streak instead of a spot.

2. All of the hexuronic acid in the fraction separated from leukocytes was associated with the nondialyzable material. The average yield of hexuronic acid from the fraction representing $10^{10}$ leukocytes was $1,180 \pm 51.6$ (S.E.) gamma in males, $910 \pm 47.5$ (S.E.) gamma in females. The difference was small but significant $(\mathrm{p}<0.01)$.

3. Not all of the hexosamine in the fraction separated from leukocytes was associated with the non-dialyzable material. The dialyzable hexosamine component was not identified.

4. Not all of the hexuronic acid and hexosamine in the fraction separated from urine was associated with the non-dialyzable material. That portion of each lost on dialysis cannot be regarded as be- 
ing a component of an acid mucopolysaccharide. After dialysis of the fraction, no difference in quantity of non-dialyzable material was found between males and females.

\section{ACKNOWLEDGMENT}

The technical assistance of Mrs. Elizabeth Corcoran and Miss Sarah Hart is gratefully acknowledged.

\section{REFERENCES}

1. Kerby, G. P., The excretion of glucuronic acid and of acid mucopolysaccharides in normal human urine. J. Clin. Invest., 1954, 33, 1168.

2. Bassiouni, M., The estimation of heparin and similar substances in human blood and tissues using a combined biological and colorimetric method with paper electrophoretic studies. J. Clin. Path., 1954, 7, 330.

3. Astrup, P., On the determination of heparin in blood plasma and urine. Acta pharmacol. et toxicol., 1947, 3, 165.

4. Craddock, J. G., Jr., and Kerby, G. P., Urinary excretion of acid mucopolysaccharides by diabetic patients. J. Lab. \& Clin. Med., In press.
5. Dische, Z., A new specific color reaction of hexuronic acids. J. Biol. Chem., 1947, 167, 189.

6. Elson, L. A., and Morgan, W. T. J., CCXLVIII. A colorimetric method for the determination of glucosamine and chondrosamine. Biochem. J., 1933, 27, 1824.

7. Pasternak, C. A., and Kent, P. W., Paper electrophoresis of chondroitin sulphates and other acidic carbohydrates. Research, 1952, 5, 486.

8. Leitner, J. G., and Kerby, G. P., Staining of acid mucopolysaccharides after chromatography on filter paper. Stain Technol., 1954, 29, 257.

9. Rossiter, R. J., and Wong, E., $\beta$-glucuronidase of rabbit polymorphonuclear leucocytes. Canad. J. Research, Sec. E., 1950, 28, 69.

10. Dziewiatkowski, D. D., Effect of age on some aspects of sulfate metabolism in the rat. J. Exper. Med., 1954, 99, 283.

11. Follette, J. H., Valentine, W. N., Hardin, E. B., and Lawrence, J. S., Studies on the glucuronic acid content of human leukocytes in health and in disease. J. Lab. \& Clin. Med., 1954, 43, 134.

12. Thomas, L., and Good, R. A., Studies on the generalized Shwartzman reaction. I. General observations concerning the phenomenon. J. Exper. Med., 1952, 96, 605. 